\title{
Granular-Cell Tumor of Trachea Masquerading as Hurthle-Cell Neoplasm on Fine-Needle Aspirate: A Case Report
}

\author{
Esperanza B. Kintanar, M.D., ${ }^{1}$ Thomas J. Giordano, M.D., Ph.D., ${ }^{1}$
} Norman W. Thompson, M.D., ${ }^{2}$ and Claire W. Michael, M.D. ${ }^{1 *}$

\begin{abstract}
We report on a case of extraluminal tracheal granular-cell tumor which was interpreted as a Hurthle-cell neoplasm of the thyroid on fine-needle aspirate. Review of the literature reveals only one other such case. The patient was a 35-yr-old female who presented with an enlarged thyroid. Aspiration cytology revealed a syncytium of cells with abundant granular cytoplasm interpreted as a thyroid follicular neoplasm with Hurthle-cell change. However, histology of the resection specimen with immunohistochemistry confirmed it as a granular-cell tumor. The cytologic differential diagnosis of neoplasms with oncocytoid cytoplasm in and around the thyroid should include granular-cell tumor of the trachea. Diagn. Cytopathol. 2000;22:379-382. ๑ 2000 Wiley-Liss, Inc.
\end{abstract}

Key words: granular-cell tumor; Hurthle-cell tumor; oncocytoid cells; fine-needle aspirate; thyroid; trachea

Granular-cell tumors (GCTs) may occur anywhere in the body. About 50\% are found in the submucosal and subcutaneous tissues of the head and neck region and oral cavity. ${ }^{1,2}$ They have also been described as lesions of the respiratory tract, ${ }^{3}$ gastrointestinal tract, ${ }^{4}$ genitourinary tract,,${ }^{5,6}$ and breast. ${ }^{7}$

GCTs in the laryngotracheal tree can clinically present as a thyroid nodule and may produce symptoms which are usually associated with primary lesions of the thyroid. Thus, GCT should be considered in the differential diagnosis of nodules aspirated from the anatomic vicinity of the thyroid. We describe such a case in which the cytology of a granu-

\footnotetext{
${ }^{1}$ Department of Pathology, University of Michigan Hospitals, Ann Arbor, Michigan

${ }^{2}$ Department of Surgery, University of Michigan Hospitals, Ann Arbor, Michigan

* Correspondence to: Claire W. Michael, M.D., Department of Pathology, University of Michigan Medical Center, 1500 E. Medical Center Drive, Room 2G332/Box 0054, Ann Arbor, MI 48109-0054.

E-mail: clairemi@umich.edu

Received 21 July 1999; Accepted 1 December 1999
}

lar-cell tumor of the trachea masqueraded as an oncocytic thyroid neoplasm on fine-needle aspirate.

\section{Case Report}

The patient was a 35-yr-old female who presented with an enlarged thyroid associated with decreased energy level and premature atrial contractions. Physical examination revealed a palpable nodule clinically felt as originating from the right lower pole of the thyroid. Fine-needle aspiration of the nodule was performed. The aspirate was interpreted as a thyroid follicular neoplasm with Hurthle-cell (oncocytic) change.

The patient was admitted for surgery and was found to have a nodule posterior to the thyroid between the trachea and esophagus. She underwent right thyroid lobectomy, pyramidal lobectomy, isthmusectomy, and resection of a paratracheal lymph node.

\section{Cytologic and Pathologic Findings}

The aspirate was low in cellularity, and colloid was not identified. It consisted of syncytial fragments and small loose clusters of cells with abundant granular amphophilic cytoplasm and ill-defined borders (Fig. 1A). Nuclei were eccentric, and uniformly round to oval. Nuclear borders were smooth, chromatin was finely granular, and nucleoli were inconspicuous (Fig. 1B).

Grossly, there was a discrete, encapsulated, and yellowwhite firm nodule measuring $2.2 \times 1.4 \mathrm{~cm}$ which was attached to the right lobe of thyroid. However, there were no nodules within the thyroid parenchyma. The histology of the nodule shared similarities with its cytologic features. The nodule consisted of anastomosing nests of large epithelioid cells entrapping benign seromucous glands, with occasional spindle forms and intervening fibrosis (Fig. 2A). Nuclear pleomorphism was not present. The cells were 
A

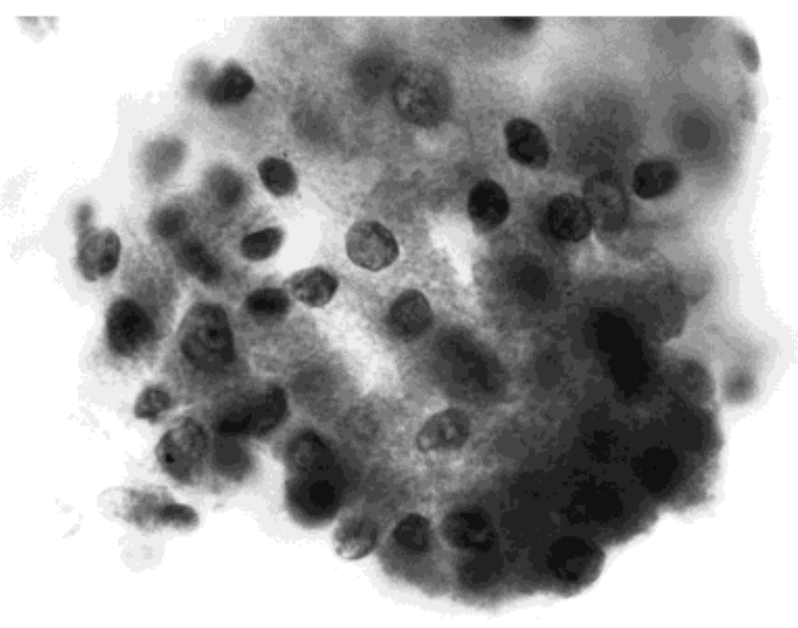

B

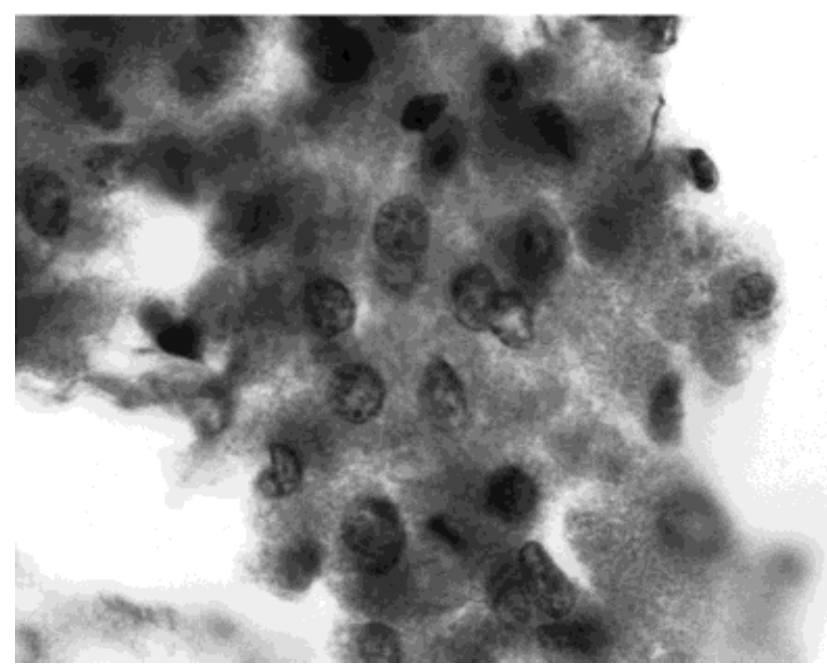

Fig. 1. A: Aspirate of granular-cell tumor. Note syncytium of cells with ill-defined borders and abundant granular amphophilic cytoplasm (Papanicolaou stain, $\times 1,000)$. B: Cells comprising GCTs are uniform in size and have eccentric, uniformly round to oval nuclei; with smooth nuclear borders, finely granular chromatin, and inconspicuous nucleoli (Papanicolaou stain, $\times 1,000)$.

distended by amphophilic, finely granular cytoplasm which was PAS-positive and resistant to diastase digestion.

Immunoperoxidase stains for S-100 protein, neuronspecific enolase, and vimentin were positive; CEA was negative (Fig. 2B). Accordingly, the nodule was diagnosed as an extraluminal tracheal granular-cell tumor since it did not involve the thyroid parenchyma and was adjacent to the trachea, entrapping tracheal submucosal glands. The sections of the paratracheal lymph node and thyroid tissue were unremarkable. Oil red-O stain was negative, excluding a parathyroid adenoma from the differential diagnosis.

\section{A}

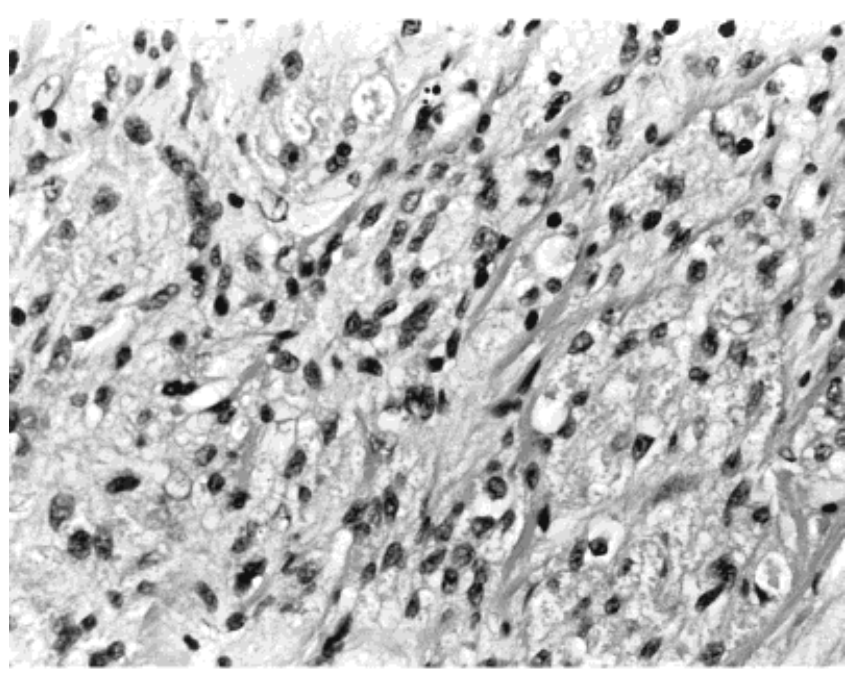

B

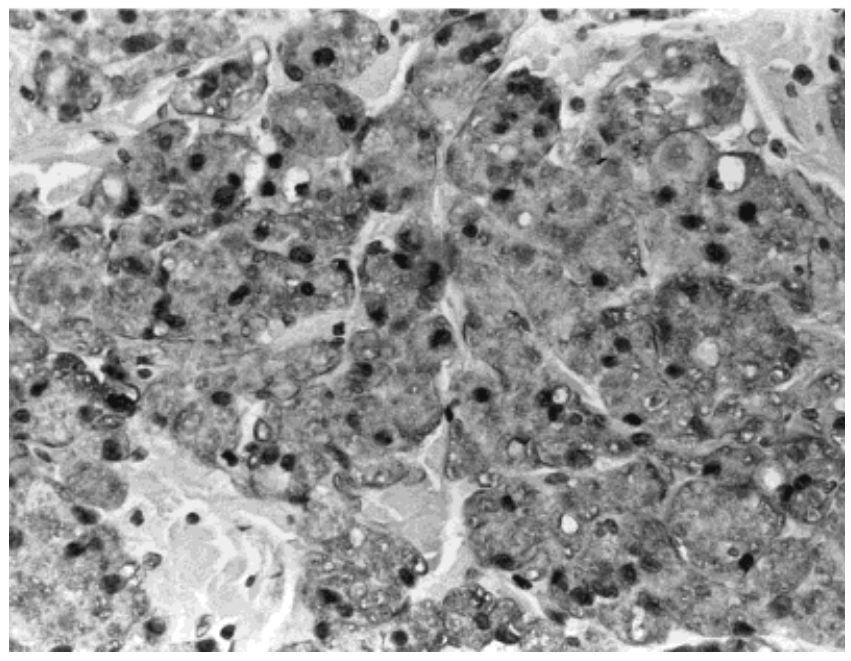

Fig. 2. A: Histology of extraluminal tracheal granular-cell tumor. The nodule consists of anastomosing nests of large epithelioid cells with occasional spindle forms and intervening fibrosis. Note entrapped benign glands from tracheal submucosa $(H \& E$ stain, $\times 400)$. B: Diffuse, strong staining of GCT with S-100 immunoperoxidase $(\times 400)$.

\section{Discussion}

Granular-cell tumors are usually benign neoplasms, especially those which measure less than $3 \mathrm{~cm}$ in diameter. Only an estimated $1-2 \%$ are reported to be malignant.

Heterogenous cell differentiation with expression of different epitopes has been suggested as their histogenesis, ${ }^{8}$ but the currently accepted theory is that GCTs originate from a precursor of the Schwann cell or neural crest cell.

Although GCTs may occur throughout the body, only $11 \%$ were reported to occur in the respiratory tract. In this location, GCTs involve the larynx and bronchi more than the trachea..$^{9,10}$ There are only 30 described cases occurring in the trachea as reported in the English-language litera- 
ture. ${ }^{11}$ Twenty percent of these cases have multiple lesions. About $60 \%$ occur in its cervical portion, of which $73 \%$ present as intraluminal tumors, $17 \%$ as extraluminal, and $10 \%$ with both components. Since these tumors are localized in the tracheobronchial tree, they may present as large midline neck nodules and clinically mimic thyroid disease by producing hoarseness or pressure symptoms. However, the occurrence of GCTs in the thyroid, usually as asymptomatic and painless masses, is even less frequent. In the archives of the Armed Forces Institute of Pathology only 1 out of 145 cases with GCTs of the head and neck was of thyroid origin. ${ }^{1}$

The first reported case of granular-cell tumor of the thyroid which had to be differentiated from a Hurthle-cell neoplasm (HCN) was in an 11.5-yr-old girl receiving highdose estrogen treatment for familial tall stature since she was 9 yr old. ${ }^{12}$ She developed a firm nodule in the middle of the right thyroid lobe which was confirmed by ultrasound as a hypoechoic mass. Total thyroidectomy revealed a firm $1.5 \times 1.2 \mathrm{~cm}$ nodule in the midportion of the right lobe of thyroid. The histology was a straightforward GCT, but a Hurthle-cell neoplasm was considered due to its epithelioidcell appearance and prominent eosinophilic granular cytoplasm. The neoplastic cells stained positive with S-100 and negative with thyroglobulin, supporting the diagnosis of GCT.

Review of the literature further reveals only one reported case of a tracheal granular-cell tumor, which was diagnosed on fine-needle aspirate as a follicular thyroid neoplasm. ${ }^{11}$ The patient was a 37-yr-old female who presented with a right neck mass. Thyroid scan revealed a cold nodule extending across the midline. Flexible bronchoscopy revealed external compression of the right side of the trachea with no intraluminal lesions. She underwent total thyroidectomy for a $4 \times 3 \mathrm{~cm}$ nodule in the medial portion of the right lobe of the thyroid which appeared to grossly invade the trachea. The nodule consisted of polygonal cells with prominent granular cytoplasm that stained positive with S-100. The final histologic diagnosis was extraluminal tracheal granular-cell tumor growing into the thyroid gland.

We report another case of extraluminal tracheal granularcell tumor, presenting clinically as a thyroid nodule, which was mistaken for a Hurthle-cell neoplasm of the thyroid on fine-needle aspirate. The cytologic findings in our case are similar to those previously reported:13-15 loose sheets and clusters of granular cells with abundant cytoplasm and indistinct borders; and usually, eccentric, round, or spindleshaped nuclei with inconspicuous nucleoli. In this case, the composite features of syncytial fragments and loose clusters of cells with abundant granular (oncocytoid) cytoplasm, without background colloid, were mistaken for Hurthle-cell change. Certain cytologic features, however, may help differentiate granular-cell tumors from Hurthle-cell neoplasms (HCNs). Classic Hurthle cells are large with characteristic

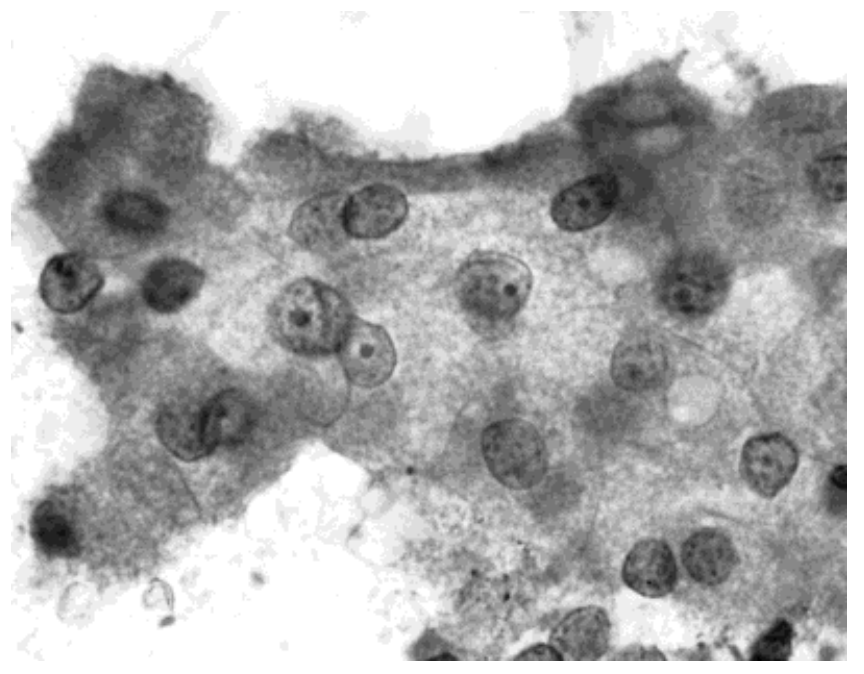

Fig. 3. Aspirate of Hurthle-cell tumor of thyroid. Cell borders are welldefined, and cell size is variable, with coarser granular cytoplasm. Nuclear size and positioning may vary. Note prominent nucleoli and invariably coarse chromatin (Papanicolaou stain, $\times 1,000$ ).

abundant, coarse granular cytoplasm and prominent macronucleoli. Binucleate forms may be present. Within syncytial fragments, cell size is variable, with well-defined cellular borders. The nuclear size is variable and in addition, nuclear position varies from slightly eccentric to central. Nuclear borders have subtle irregularities, and chromatin varies from finely to coarsely granular (Fig. 3). ${ }^{16}$

In difficult cases, ancillary immunoperoxidase stains may help distinguish GCTs from HCNs. GCTs have been consistently found to stain positive with neuron-specific enolase (NSE) and negative with cytokeratin, ${ }^{8}$ while Hurthle cells stain negative with NSE and have patchy positive staining with thyroglobulin. ${ }^{18}$

Whereas GCTs are usually also positive with S-100 protein, vimentin, and CEA, there have been conflicting reports concerning the immunoreactivity of Hurthle cells with these stains. ${ }^{17,18}$ Abu-Alfa et al. reported from $94-100 \%$ strong diffuse nuclear and cytoplasmic staining of 18 Hurthle-cell tumors with S-100, ${ }^{19}$ but Kanthan and Radhi found that none of 25 cases of thyroid adenomas with Hurthle cells were immunoreactive with S-100. ${ }^{17}$ Kanthan and Radhi also reported that Hurthle cells stained moderately positive with low molecular weight keratin but negative with CEA. This was in contrast to the study by Chetty, in which none of 25 Hurthle-cell follicular neoplasms stained with cytokeratin CAM 5.2 but had luminal staining with CEA. ${ }^{18}$

Nonetheless, ultrastructural studies would definitely be able to differentiate both neoplasms: the cytoplasm of Hurthle-cell tumors is packed with mitochondria showing structural abnormalities, while granular-cell tumors have autophagosomes, angulate bodies, and sometimes tumorcell processes invaginating other cell processes, reminiscent of the Schwann cell-axon relationship. ${ }^{8}$ 
In conclusion, GCTs can occur in the tracheobronchial tree, and should be considered in the differential diagnosis of nodules from the vicinity of the thyroid when a fineneedle aspirate yields large cells with abundant granular cytoplasm (oncocytoid). The cytologic difficulty in this case was in differentiating a granular-cell tumor from a Hurthlecell (oncocytic) neoplasm of the thyroid. GCTs, however, have distinct cytologic features which if strictly applied should not be confused with a Hurthle-cell neoplasm of the thyroid. Although the histology of GCT is usually straightforward, immunoperoxidase stains and/or ultrastructural studies may help differentiate these tumors from Hurthlecell neoplasms. Finally, GCT is usually a benign tumor which, if correctly diagnosed, would preclude unnecessary radical surgery. Thyroid lobectomy or tracheal resection/ shaving with endoscopic excisions appears to be the surgical treatment for tracheal GCTs. ${ }^{20}$ Complete excision is usually curative.

\section{References}

1. Fliss DM, Puterman M, Zirkin H, Leiberman A. Granular cell lesions in head and neck: a clinicopathological study. J Surg Oncol 1989;42: 154-160.

2. Peterson LJ. Granular-cell tumor review of the literature and report of a case. Oral Surg 1974;37:728-735.

3. Compagno J, Hyams VJ, Ste-Marie P. Benign granular cell tumors of the larynx. A review of 36 cases with clinicopathologic data. Ann Otol 1975;84:308-314.

4. Johnston J, Helwig EB. Granular cell tumors of the gastrointestinal tract and perianal region. A study of 74 cases. Dig Dis Sci 1981;26: 807-816.

5. Mouradian JA, Coleman JW, McGovern JH, Gray GF. Granular cell tumor (myoblastoma) of the bladder. J Urol 1974;112:343-345.
6. Fletcher MS, Aker M, Hill JT, Pryor JP, Whimster WF. Granular cell myoblastoma of the bladder. Br J Urol 1985;57:109-110.

7. Hahn HJ, Iglesias J, Flenker H, Kreuzer G. Granular cell tumor in differential diagnosis of tumors of the breast. The role of fine needle aspiration cytology. Pathol Res Pract 1992;188:1091-1094.

8. Ulrich J, Heitz PU, Fischer T, Obrist E, Gullotta F. Granular cell tumors: evidence for heterogeneous tumor cell differentiation. Virchows Arch [B] 1987;53:52-57.

9. Subbuswamy SG. Granular cell tumour of trachea: report of a case. Br J Dis Chest 1979;73:85-88.

10. Benson WR. Granular cell tumors (myoblastomas) of the tracheobronchial tree. J Thorac Cardiovasc Surg 1966;52:17-30.

11. Burton DM, Heffner DK, Patow CA. Granular cell tumors of the trachea. Laryngoscope 1992;102:807-813.

12. Mahoney CP, Patterson SD, Ryan J. Granular cell tumor of the thyroid gland in a girl receiving high-dose estrogen therapy. Pediatr Pathol Lab Med 1995;15:791-795.

13. Glant MD, Wall RW, Ransburg R. Endobronchial granular cell tumor. Cytology of a new case and review of the literature. Acta Cytol 1979;23:477-482.

14. Chen KTK. Cytology of bronchial benign granular-cell tumor. Acta Cytol 1991;35:381-384.

15. Mermolja M, Rott T. Cytology of endobronchial granular cell tumor. Diagn Cytopathol 1991;7:524-526.

16. Kini SR. Guides to clinical aspiration biopsy. Thyroid. New York: Igaku-Shoin Medical Publishers, Inc.; 1996. p 105-126.

17. Kanthan R, Radhi JM. Immunohistochemical analysis of thyroid adenomas with Hurthle cells. Pathology 1998;30:4-6.

18. Chetty R. Hurthle cell neoplasms of the thyroid gland: an immunohistochemical study. Histopathology 1990;17:368-370.

19. Abu-Alfa AK, Straus FH II, Montag AG. An immunohistochemical study of thyroid Hurthle cells and their neoplasms: the roles of S-100 and HMB-45 proteins. Mod Pathol 1994;7:529-532.

20. Mikaelian DO, Cohn H, Israel H, Jabourian Z. Granular cell tumor of the trachea. Ann Otol Rhinol Laryngol 1984;93:457-459. 